Fifth International Conference on Sustainable Construction Materials and Technologies. http://www.claisse.info/Proceedings.htm

$5^{\text {th }}$ International Conference on Sustainable Construction Materials and Technologies (SCMT5)

Kingston University London, UK | 14-17 July 2019

\title{
A SUSTAINABLE PROCESS FOR MASS CUSTOMIZATION IN THE WOODWORKING INDUSTRY
}

Stehling, Miguel Pereira

Universidade Estadual de Campinas-UNICAMP-Brazil-miguelstehling @ hotmail.com Ruschel, Regina Coeli Universidade Estadual de Campinas-UNICAMP - Brazil - ruschel@fec.unicamp.br

\begin{abstract}
From the perspective of a fabricator of custom components for buildings, one of the key benefits of using Building Information Modeling (BIM) is for the purpose of obtaining a seamless integration between Design and Fabrication; and this integration is one of the key drivers for sustainable manufacturing within a mass customization strategy. This paper presents the current stage of an Action Research proposing a method to solve some problems faced by woodworking manufacturers trying to implement mass customization. The method will enhance sustainability through 3D models that will allow minimization of construction defects, design delay, and wastage. The method will also improve sustainability as a result of clearer design communications, and precision on a bill of material. An important result already achieved in this research is that the designers and engineers of the company are already working collaboratively and committed to the implementing of a new technology towards Mass Customization.
\end{abstract}

Keywords: Mass Customization, Digital Fabrication, Prefabrication, BIM, Sustainability

\section{INTRODUCTION}

The manufacturing system has evolved from craftsmanship going through mass production to lean manufacturing and Mass Customization (MC). Handcrafts were unique but had a high cost. Mass production brought low cost and low variety. Lean manufacturing minimized waste and MC came to increase variety, keeping the lowcost and efficiency of Mass Production. Engineered-To-Order (ETO) is a product designed and fabricated to meet customer requirements and is a typical operation of Small and Medium Sized Enterprises (SME). Building Information Modeling (BIM) is 
a digital model and process that includes collaboration among disciplines in the Architecture, Engineering, and Construction (AEC) industry. According to Eastman et al. (2008), BIM provides the vast amount of information required for the fabrication of customized building components. Eastman stated that BIM is an ETO enabler, but the use of automated machines in ETO fabrication is still uncommon.

According to Hermann et al. (2014), MC is a combination of three principles: The first is called modularization which allows a wide variety of products through the recombination of parts. The second principle is the ability to quickly adjust the structure of production. And the third principle is delaying the point where a product becomes unique. In the opinion of Kieran and Timberlake (2004), MC is a hybrid process of customization and mass production that proposes an automated fabrication of unique products. And Farr et al. (2014) add to the MC concept, the efficiency and high volume of mass production. In order to increase the potential for customization, Stralen (2015) emphasizes the need to shift the project's focus from the object to the process.

Digital Fabrication (DF) is a manufacturing technology through automated machines and has evolved from the first machines programmed with G-Code to the web-based Industry 4.0 paradigm. DF has been widely used in the production of standardized building components, but not for the production of customized components. In the opinion of Farr et al. (2014), Web-based databases and BIM can be helpful for the MC strategy in the AEC industry. Luth (2011) states that the current interoperability between softwares, adopted in the AEC industry, has excessive representations of database objects. Farr et al. (2014) concluded that for the AEC industry, researches in user-friendly web database applications are still needed.

Hermann et al. (2014), stated that the three dimensions of sustainability - economics, ecology, and society - should be improved in manufacturing in four main aspects: Integrated systems, adaptability, web-based production, and collaborative work. Integrated systems keep the balance between efficiency and effectiveness. Adaptability addresses the demand for an increasing variety and complexity of products. Web-based production technology provides live information of the systems. Collaborative work yields a friendly environment in SMEs. SME owners remain unconvinced that costs can be reduced by making environmental improvements. They fear that the costs of environmental improvements will affect their competitiveness.

According to Bruno et. al., (2013), some factors indicate that mass customized products are less sustainable than standardized products, while other factors suggest the opposite. Pedrazzoli et.al., (2011) suggested that additional investigations are needed to conclude that $\mathrm{MC}$ is a driver for improvement in sustainability. The study of Trentin, Forza, and Perin, (2015) found links between MC and sustainability and concluded that research on this subject is still limited. According to Medini, Da-Cunha, and Bernard, (2011), MC and Sustainability need to be assessed together in order to strengthen both of them. Tyl, Lizarralde, and Allais, (2015) concluded that economic activities that use locally available resources and generate products for the local community have a great role to play in sustainability. 
Hora et al., (2016) performed a theoretical conceptualization identifying five MC enablers and six Sustainability enablers. The MC enablers are Co-creation, Modularity, Platform, Build-to-Order, and Postponement. Co-creation is the involvement of customers in the design process. Modularity stands for the modular combination of components of an object. Platform denotes the interaction between stakeholders. Buildto-Order means to start producing when an order is received. The Postponement means to delay the point in which the product becomes unique. The Sustainability enablers identified by Hora are Longevity, Eco-design, Efficiency, Circular economy, Dematerialization, and Awareness. Longevity is to increase the lifespan of the product; Eco-design stands for implementing strategies for continual environmental improvement. Efficiency denotes increasing the usefulness of material and energy in the product lifecycle. Circular economy means to circulate materials and components among a broad production chain. Dematerialization is to create more value with less material usage. Awareness means the knowledge of sustainable values and impacts.

Table 1 shows the cross-reference between MC enablers and sustainability enablers, through which Hora et al. (2016), proposed a framework for integrating Sustainability on an MC strategy. The framework comprises a set of seven generic patterns: 1 - The ability in defining the point from which the customer can choose to individualize a product; 2-Incorporation of sustainable choices in the user interface; 3- Product recyclable or upgradable; 4-Produce only what can be sold; 5-Product longevity, efficient energy and material usage; 6- The manufacturer providing a solution for the product at the end of its lifecycle; 7- Renewable energy. It can be concluded by the analysis of Table 1, that among the MC enablers, Platform is the most strongly linked to Sustainability. Platform means interaction between designer, manufacturer, and customer and is one of the objectives in this research.

Table 1: Framework for integrating MC and Sustainability. Source: Adapted from Hora et al., (2016)

\begin{tabular}{|c|c|c|c|c|c|}
\hline \multirow{2}{*}{\multicolumn{2}{|c|}{$\begin{array}{c}\text { Framework for } \\
\text { integrating Mass } \\
\text { Customization and } \\
\text { Sustainability }\end{array}$}} & \multicolumn{4}{|c|}{ Mass Customization Enablers } \\
\hline & & \multirow[t]{2}{*}{$\begin{array}{l}\text { Co- } \\
\text { Creation }\end{array}$} & \multirow[t]{2}{*}{ Modularity } & \multirow{2}{*}{$\begin{array}{l}\text { Platform } \\
2,6 \text {, and } 7\end{array}$} & $\begin{array}{l}\text { Built-to- } \\
\text { Order and } \\
\text { Postponement }\end{array}$ \\
\hline \multirow{6}{*}{ 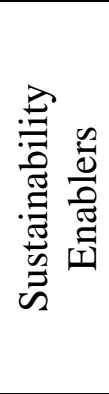 } & Longevity & & & & \\
\hline & Eco-Design & $\begin{array}{c}1,3 \text {, and } \\
5\end{array}$ & 1 & 3 & \\
\hline & Efficiency & 5 & & & 4 \\
\hline & $\begin{array}{l}\text { Circular } \\
\text { Economy }\end{array}$ & & 2 & 2 and 6 & \\
\hline & Dematerialization & & & 6 and 7 & \\
\hline & Awareness & 3 and 5 & & 3 & \\
\hline
\end{tabular}

The problem identification in this research comes from the interest to find solutions to practical problems faced by manufacturers of customized prefabricated building 
components. The main objective is through an action research, to develop a method to implement BIM integrated to the MC strategy for small and medium enterprises.

\section{METHODOLOGY}

This study presents the current stage of an Action Research within the bigger scenario of a Design Science Research of a doctoral thesis. The research aims to design, develop and evaluate a method for implementing MC for fabricators of ETO products within the SME sector of the AEC industry. The research has the objective to show that from the perspective of a fabricator of custom components for buildings, one of the key benefits of using BIM is for the purpose of obtaining an integration between design and fabrication. As claimed by Hora et al., (2016), integration between design and fabrication is a driver of MC. This study adopts the statement of Pourabdollahian et al., (2014), that customization that offers unlimited choices to the client, is economically and environmentally unfeasible.

The Action Research is being conducted in the environment of an SME designer and fabricator of ETO components, specialized in custom kitchens. One of the researchers in this study has previous experience in software development for the design and fabrication of kitchen and bathroom in an SME manufacturer. This knowledge has allowed the researcher being more participative and interpretative in the Action Research. The researcher plays an active role in the studied company because he has a good knowledge of the roles of each specialist. The protocol for the research is summarized in Table 2. In the first cycle of the Action Research, meetings were held with key employees to draw guidelines. For the design phase, BIM models and a Webbased interface were developed. The BIM tools used were Revit and Dynamo. The Web application was developed using HTML / PHP / MySQL. At the fabrication phase, BIM models were exported to CNC machines. The maker of the CNC machines is BIESSE who developed a programming language called Biesseworks. Text files were exported from BIM tools to Biesseworks.

Table 2: Protocol for the research Source: Author

\begin{tabular}{|c|c|}
\hline Item & Description \\
\hline Research participants. & $\begin{array}{l}\text { The researcher, the firm's CEO, design and production } \\
\text { engineers, the CAD manager, the database administrator, } \\
\text { and the CNC programmer. }\end{array}$ \\
\hline Approach. & Qualitative, verbal description of the phenomena observed. \\
\hline \multirow[t]{4}{*}{ Steps to be performed } & Plan / design; \\
\hline & Act / development \\
\hline & Observation / Evaluation \\
\hline & Reflection / lessons learned \\
\hline $\begin{array}{l}\text { Analysis and } \\
\text { interpretation of data }\end{array}$ & $\begin{array}{l}\text { Participant observation, interviews, and project's } \\
\text { documents. }\end{array}$ \\
\hline
\end{tabular}

\section{RESULTS}


The research is being conducted in two cycles of four stages. Planning is the first stage in which artifacts are designed. Action is the second stage in which artifacts are developed. The third stage is called Observation, which means evaluation of artifacts, and the fourth stage is called Reflection in which the lessons learned in the cycle are pointed out. At the closing of the current study, the research is at the end of the first cycle. The entire process in the first cycle was documented to form the basis for the second cycle. The configuration of a very simple kitchen was planned. The layout comprises five modules shown in Figure 1, whose sketches are shown in Figure 2 and Figure 3. A box with two drawers under the stove, and a box with two doors under the sink. Between stove and sink, there is a left-swing-door. On the far right, there is a box with a door swinging right and a drawer on top. Beside this cabinet, there is a threedrawer box.

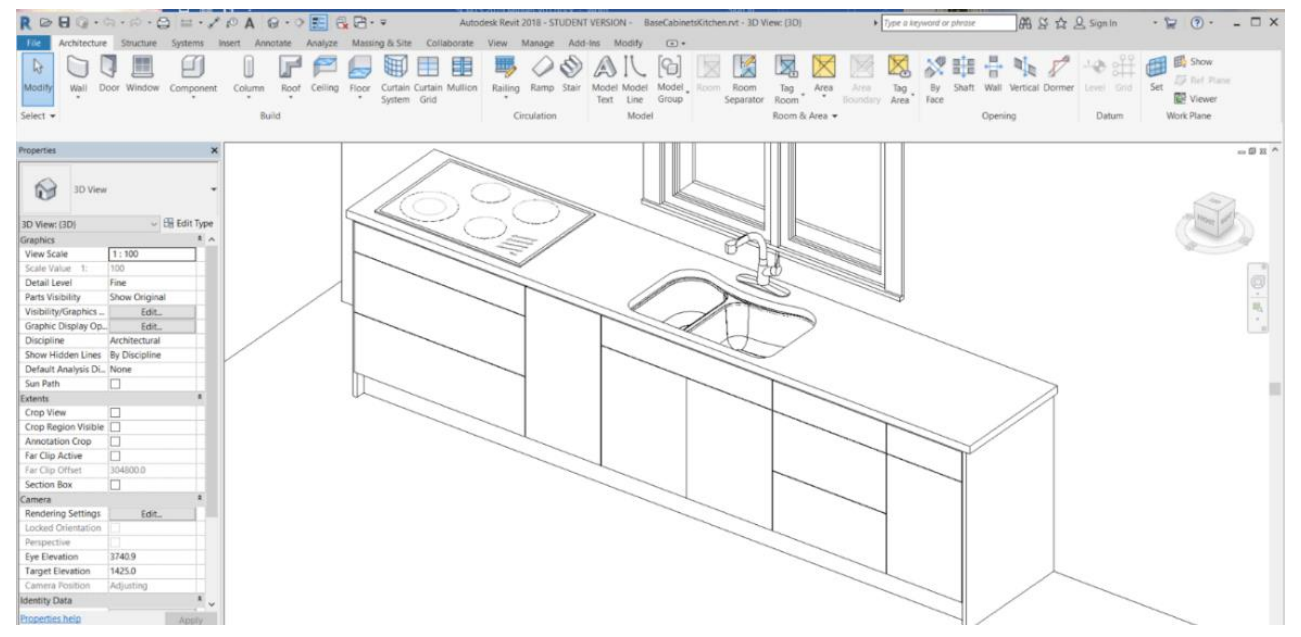

Figure 1: First cycle of Design aiming Mass Customization

Source: Author
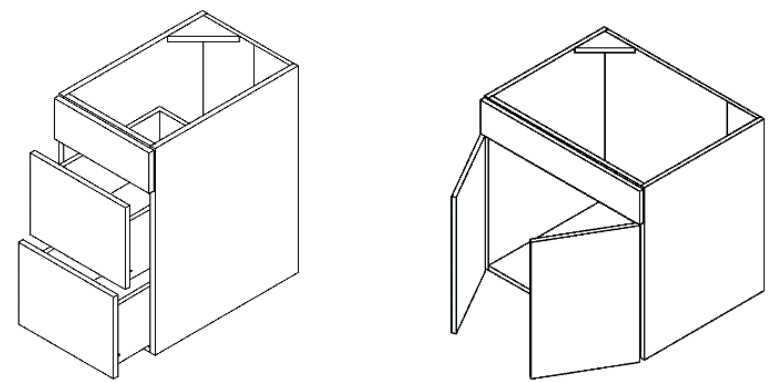

Figure 2: Two-drawers under stove and two-doors under sink

Source:Author 

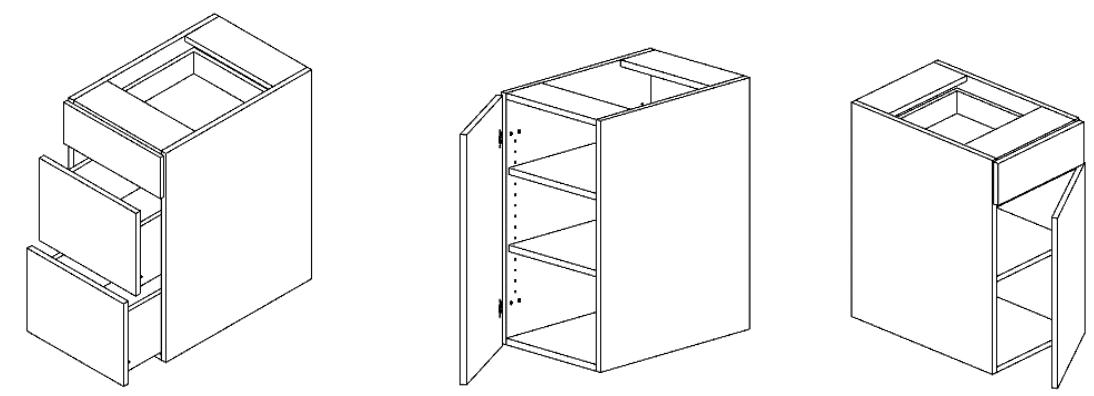

Figure 3: Three-drawers, left-swing-door, right-swing-top-drawer Source: Author

The first stage of the first cycle was a reflection conducted through an analysis of the results of a case study performed prior to this investigation. Meetings were held with key employees of the company surveyed and research guidelines were developed. For the design phase, BIM models and a Web-based interface were developed. In the second stage, a method of design and fabrication of customized kitchens was proposed, a BIM adoption strategy was planned, and tools were chosen. The method follows the concept of Luth (2011) according to which there is a need for more simplified databases in the AEC industry.

In the opinion of Farr et al. (2014), researches in user-friendly web database applications are still needed in the AEC industry. According to the method developed, the customization of kitchen cabinets begins with designers completing a web-based database containing information and design constraints. According to Khalili-Araghi and Kolarevic (2016), the integration between geometry and data could match customer preferences with product specification and technical constraints. This integration began in the first cycle and is deepened in the second cycle of the research. In first cycle the system was developed in VisualBasic. The web database application was developed using HTML/PHP accessing a MySQL database. The web application was planned for the second cycle. Figure 4 shows a sample of this system which was developed by the researcher in the NetBeans IDE8.1 environment. The database administration was performed with the XAMPP Control Panel V.3.2.2. Due to the fact that designers in the studied company are already proficient with the VisualBasic tool, this language was used in the first cycle of the Action-Research for the development of the project information system. VisualBasic is a text-based programming language commonly used by software developers. This action aims to simplify the current interoperability among software in the AEC industry, which, according to Luth (2011), contains excessive representations of database objects. The next step was the creation of a schematic three-dimensional model. In this research, Revit and Dynamo were the selected tools. Revit is a modeling software for the AEC industry, and Dynamo is a visual programming language native in Revit. 

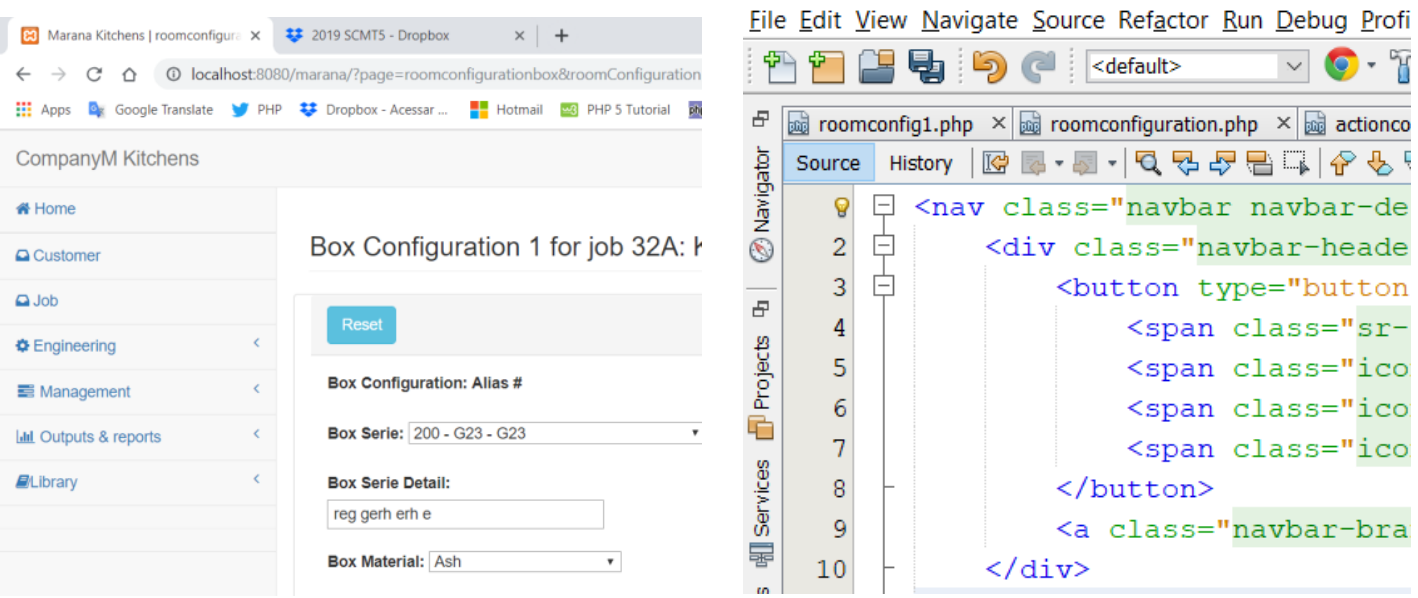

Figure 4: Web database application face-NetBeans IDE8.1.

Source: Author

Due to the varying nature of a custom product, the method being developed is aiming to facilitate the update and maintenance of the cabinetry Library. It's been applied here the principle of hierarchy, under which each component inherits geometry, parameters, and constraints. At the top of that hierarchy, there is a group called Category. Categories are the macro elements of a building such as walls, doors, floors, furniture, and appliances. The cabinetry library will be built under a Category called Component. Each Category has groups of Families associated with it. A family is a group of elements with a common set of Parameters (properties), identical use, and similar geometry. But Family is still a very broad level in the hierarchy. So, each variation of a Family is referred to as a Type. Finally, the actual objects in a building model are called Instances. So, one can say that an Instance belongs to a Type, Type, in turn, belongs to a Family, and Family is part of a Category. For example, in the kitchen cabinetry library, there will be, among others, one family called Base-One-Door. Under this family, there will be the Base-One-Door-Left-Swing and the Base-One-DoorRight-Swing Types. Figure 5 shows six cabinets from the same family. Only the types are different.

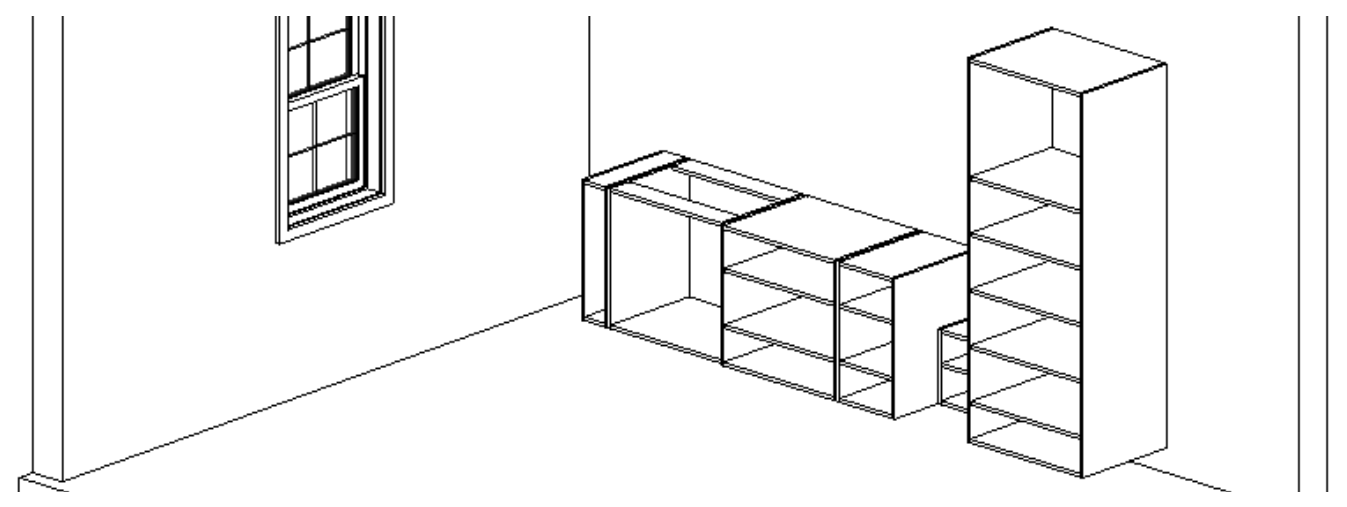

Figure 5: Cabinetry from same family, only different types Source: Author 
The project information transferred to the model encompasses, among others, interior parts material, exterior parts material, paint or stain finishing, and drawer type. Dynamo is a visual language that has a friendly interface that can be easily understood by professionals with more knowledge of woodworking than computer skills. Dynamo was used in this research to generate fabrication parameters like length, width, edge banding, and finishing. Figure 6 shows the interface of Dynamo used to export geometry and parameters to fabrication.

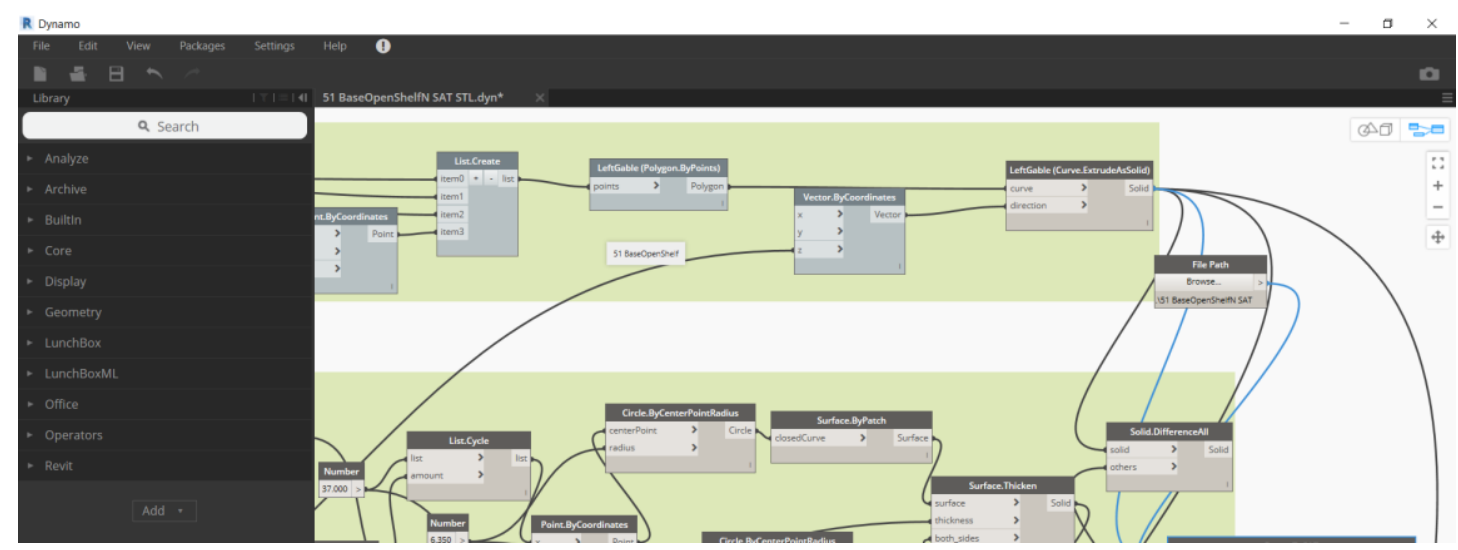

Figure 6: Dynamo exports Revit geometry and parameters.

Source: Author

The machines used for Digital Fabrication evolved from the first G-Code programmed CNC machines to the web-based Industry 4.0. At the fabrication phase of this cycle, parameters from the BIM models were exported to the $\mathrm{CNC}$ machines. The maker of the CNC machines in the studied company is BIESSE which has a proprietary programming language called Biesseworks. Text files were exported from BIM tools to Biesseworks. Biesseworks can read DXF, CIX, CID, and NC code files. Figure 7 illustrates the simulation of the fabrication of a door. In the opinion of Farr et al. (2014), Web-based databases and BIM can be helpful for the MC strategy in the AEC industry. This simulation is part of an effort to smooth the process of interoperability between BIM models and CNC machines. According to Newman (2014), a fully interoperable system is still a long way to go. 


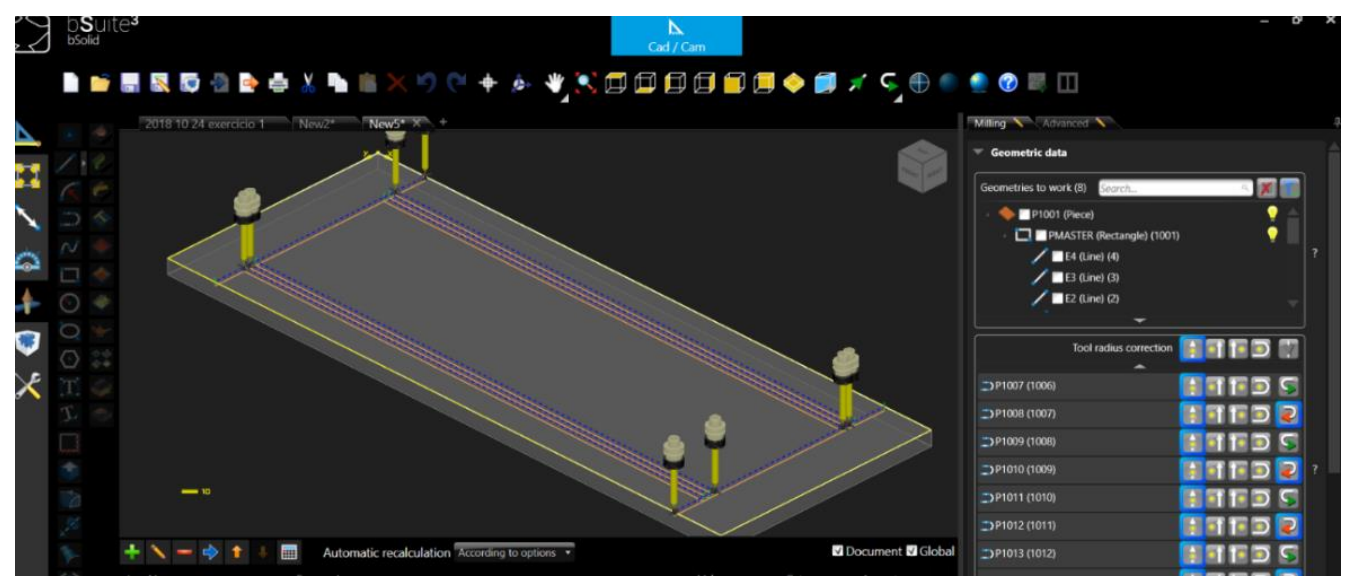

Figure 7: CNC simulation of the fabrication of a door

Source: Author

According to Schneider (2014), a Product Family is a combination of a generic structure with a set of variables and constraints designed to allow flexibility in the creation of a product. A Product Family must be consistent with the customer requirements while ensuring that no constraint is violated. Product Families are being created in this research, using the advanced algorithm concepts of Object, Class, and Method. These concepts are embedded in the Revit software. It will be a library of components suitable for future maintenance and its creation will be guided by careful planning, the choice of the right template, and parameters and constraints following predefined patterns.

The third stage of the first cycle comprised preliminary testing of the method and tools. It was accomplished through the design and digital fabrication of a limited scope of kitchen components. Only some floor cabinets with parameterized drillings. This research focuses on the concept of Bock (2015), where automation in the AEC industry is still in the innovation phase, occurring extremely slowly due to complexities of products and low R\&D budgets. Therefore, the researcher has set as the main goal for the first cycle of the Action-Research to be a phase dedicated to the unleashing in the company of a movement towards adaptability to the new technology. For a Robotoriented concept design be applied to use Digital Fabrication in Mass Customization strategy, product and process must be able to be easily changed.

The fourth stage of the first cycle was the assessment of the whole cycle. This evaluation was carried out with the team of the company studied. At this stage, information about the actions taken in the previous steps was collected and compared with the initial plan in order to find out what went wrong and what went right. At the close of this study, corrections are being made to feed the planning stage in the second cycle.

The second cycle begins with the expression of the lessons learned in the first cycle. Then a new action plan is designed based on the techniques and tools tested in the first cycle. In addition, the requirements and desired characteristics of the artifacts are reviewed in conjunction with the context in which they will operate, as well as their 
limits and relationships with the external environment. In the second cycle, the researcher, working with some of the selected employees of the company, will improve the BIM models, and the web-based database. In the last stage of the second cycle, the behavior of the artifact in relation to the solution of the problem in the real environment will be measured and evaluated.

The BIM adoption strategy contains four stages that intersect, beginning with goal setting, planning and development, and training. The first stage encompasses the definition of desired benefits, the level of detail required for design and fabrication, and how, when and by whom the component library will be created. The second stage is the planning and scheduling of activities, the effort to get staff committed, and the pace of change. The third step includes creating product families and developing and customizing the software. The fourth step is dedicated to team training to be able to assign the right person to each new role.

In order to smooth the process of adoption of BIM among SME, the choice of Revit for the BIM models, and HTML / PHP and MySQL for the web database application, is mainly due to two reasons. These are tools used around the world with many resources available for staff training and there are many experts on these tools, which facilitates the hiring process. HTML / PHP have a short learning curve, and MySQL is a Relational Database Management System that uses SQL languages.

\section{DISCUSSION}

Hermann et al. (2014), stated that the three dimensions of sustainability - economics, ecology, and society - must be improved in manufacturing in four main aspects: Integrated systems, adaptability, web-based production, and collaborative work. This research addresses Integrated systems through BIM modeling towards Digital Fabrication. The adaptability aspect is sought through the creation of families of components. Web-based production is achieved through an application developed using widely used web tools, and the collaborative work aspect through engaging designers and manufacturers from the outset of the design process.

In the opinion of Hora et al., (2016), the interaction between manufacturing process specialists, customers, and other stakeholders is an enabler of MC strongly linked to Sustainability. This interaction, made possible through BIM models and Web-based application, is part of the MC method that is being developed in this research. The study of Trentin, Forza, and Perin, (2015) found links between MC and sustainability and concluded that research on this subject is still limited. Pedrazzoli et.al., (2011) stated that additional investigations are needed to conclude that $\mathrm{MC}$ is a driver for improvement in sustainability. In the second cycle of this research, measurements will be made to verify if the MC process has reduced material consumption and waste.

Tyl, Lizarralde, and Allais, (2015) concluded that economic activities that use resources available locally and generate products for the local community have a great role to play in sustainability. Web database applications and BIM models allow the design to 
be done in one location and manufacturing elsewhere, addressing the three dimensions of sustainability - economics, ecology, and society. Longhui (2018) identified 47 obstacles to the implementation of BIM, most of which are human-related and not related to technology. Therefore, the implementation of BIM is linked to social sustainability. An important result already achieved in this research is that the designers and engineers of the company are already working collaboratively and committed to the implementation of MC. This is one of the objectives in this research that is being conducted in two four-step cycles. All actions in the first cycle were documented to form the basis of the second cycle.

The company studied is an ETO that provides highly customized products. ETO products require a more detailed specification. The BIM model provided more detailed and reliable information for fabrication. Benefits are expected in assembly because the parts fit better. The primary goal of the first cycle was to get the specialists to work collaboratively. The goal was achieved. In the second cycle, it will be used a web-based database developed with HTML / PHP and MySQL to provide information to design and fabrication.

In current practice, many parts of a building are already manufactured off-site, and digital fabrication is increasing. The contribution of this research is the formulation of a solution that allows the reconfiguration of the manufacturing process. The designs will be made according to customers' specifications who may make changes late in the process. The solution is BIM-mediated MC for SME by providing insight on how to determine the appropriate level of customization for a specific product. Manufacturers will set the optimal level of customization according to customer requirements and will check the system's ability to provide this level of customization. These two apparently conflicting issues will be combined. The formulated solution will impact the design and fabrication process and the people, reducing design coordination conflicts and the necessary efforts in programming $\mathrm{CNC}$ machines. The solution involves committed designers and customers from the design stage.

\section{REFERENCES}

Bock,T. (2015). The future of construction automation: Technological disruption and the upcoming ubiquity of robotics, Automation in Construction, 59, 113-121, https: doi.org/10.1016/j.autcon.2015.07.022

Bruno, T.D., Nielsen, K., Taps,S.B., Jorgensen,K.A.,(2013) Sustainability Evaluation of Mass Customization, International Federation for Information Processing, AICT pp 175-182,

De Leon, A.P., Burry, J.,Davis, D, Williams, N, Burry, M., Wilson, M.. (2013). A Flexible Automated Digital Design For Production Workflow,Proceedings Of The 18th International Conference On Computer-Aided Architectural Design Research In Asia, 643-652, The Association for Computer-Aided Architectural Design Research in Asia (CAADRIA) ,Hong Kong , and Center for Advanced Studies in Architecture (CASA). 
Eastman,C.M., Teicholz,P., Sacks,R., Liston, K. (2008). BIM handbook: A guide to Building Information Modeling for owners, managers, designers, engineers, and contractors, Hoboken, NJ, John Wiley \& Sons, Inc, ISNB:978-0-47018528-5

Farr, E.R.P., Piroozfar, P.A.E.;Robinson, D. (2014). BIM as a generic configurator for facilitation of customisation in the AEC industry, Automation in Construction, 45, 119-125, https://doi.org/10.1016/j.autcon.2014.05.012

Gattas, J.M.,You, Z.(2016). Design and digital fabrication of folded sandwich structures, Automation in Construction, 63, 79-87, https://doi.org/10.1016/j.autcon.2015.12.002

Hermann, C., Schmidth, C., Kurle, D., Blume, S., Thiede, S., (2014), Sustainability in Manufacturing and Factories of the Future, International Journal of precision Engineering and Manufacturing-Green Technology, Vol.1, n0.4, pp.283-292, DOI: $10.1007 / \mathrm{s} 40684-014-0034-\mathrm{z}$

Hora, M., Hankammer, S., Canetta, L., Sel, S.K., Gomez, S., Gahrens, S., (2016), Designing Business Models for Sustainable Mass Customization: A Framework Proposal, International Journal of Industrial Engineering and Management, Vol. 7, no. 4, pp.143-152, available online at www.iim.ftn.uns.ac.rs/ijiem_journal.php, ISSN 2217-2661

Khalili-Araghi,S., Kolarevic,B. (2016). Development of a framework for dimensional customization system:A novel method for customer participation, Journal of Building Engineering, 5, 231-238, https://doi.org/10.1016/j.jobe.2016.01.001

Kieran, S., Timberlake,J. (2004). Refabricating Architecture, New York, NY,McGrawHill, ISBN 0-07-143321-X

Longhui, L., (2018) Building Information Modeling-Based Process Transformation to Improve Productivity in the Singapore Construction Industry (Doctoral Thesis), Department of Building-National University of Singapore,

Luth,G.P. (2011). VDC and the Engineering Continuum,Journal of Construction Engineering and Management, 137(10), 906-915, https://doi.org/10.1061/(ASCE)CO.1943-7862.0000359

Pedrazzoli, P., Canetta,L., Sorlini,M., Bettoni,A., Corti,D., Boer,C.R., (2011), Customization and Manufacturing Sustainability - General considerations and footwear investigation, Proceeding of World Conference on Mass Customization, Personalization, and Co-Creation: Bridging Mass Customization \& Open Innovation, San Francisco Airport Marriot Waterfront, Aachen University

Pourabdollahian, G., Steiner, F., Rasmussen, O.H., Hankammer, S., (2014) A Contribution toward a Research Agenda: Identifying Impact Factors of Mass Customization on Environmental Sustainability, International Journal of Industrial Engineering and Management, Vol.5,no.4, pp.169-178, Available online at www.ftn.uns.ac.rs/ijiem, ISSN 2217-2661

Schneider, H. M.(2014). Setting Up A Backtrack-Free Customisation Process For Product Families: Estabelecendo Um Processo De Customização Livre De Retrocessos Para Famílias De Produtos,Campinas, SP, Universidade Estadual de Campinas, Programa de Pos-Graducacao em Engenharia Eletrica, http://repositorio.unicamp.br/jspui/handle/REPOSIP/261226 
Shelden, D.R. (2014). Information, Complexity and the Detail,„Architectural Design, 84(4), 92-97, Special Issue: Future Details of Architecture, https://doi.org/10.1002/ad.1786

Stralen ,M.,V.(2015). The machine for living in the conversational age, Kybernetes, 44(8/9), 1388 -1396, Subject Area: Information \& Knowledge Management, ISSN:0368-492X, https://doi.org/10.1108/K-11-2014-0241, Emerald Group Publishing Limited

Tyl, B., Lizarralde, I., Allais, R., (2015) Local value creation and eco-design: A new paradigm, $7^{\text {th }}$ Industrial Product-Service Systems Conference - PSS, industry transformation for sustainability and business, available at Elsevier www.sciencedirect.com, Procedia CIRP 30 (155-160)

Trentin,A., Forza,C., Perin,E., (2015) Embedddness and path dependence of organizational capabilities for mass customization and green management: A longitudinal case study in the machinery industry, International Journal of Production Economics, Journal homepage: www.elsevier.com/locate/ijpe, 169 (253-276), http://dx.doi.org/10.1016/j.ijpe.2015.08.011 